\title{
Depictive and other secondary predication in Lao
}

\author{
NICHOLAS J. ENFIELD
}

Lao (South-Western Tai, Laos/Thailand/Cambodia) is a typical isolating language, lacking inflectional morphosyntactic categories such as casemarking and agreement. It is of interest from a crosslinguistic perspective on depictive secondary predication, since most analyses of depictive expressions in other languages appeal largely to morphosyntactic patterns of agreement and finiteness, which are not overtly marked in Lao.

\subsection{Preliminaries on Lao grammar}

I begin by presenting some facts about the grammar of Lao which are relevant to a discussion of depictive and other secondary predication. These concern the nature of word classes, the nature of complex predication, and the general under-determination of distinctions in grammatical relationships, leading to heavy context-dependence of interpretation.

One large formally defined word class is the verb class. Words in this class express a range of concepts which in English are expressed in three distinct word classes: verb, adjective, and adverb. Grammatically, verbs take direct negation with the negator bò̀, may be marked by the preverbal progressive marker kamlang2 and the postverbal perfective marker lèew4 as well as other tense/aspect/modality markers, and may freely function as unmarked modifiers in noun phrases. Minor sub-distinctions within this class may be established (e.g. accessibility to certain types of reduplication), and these correspond to distinctions more markedly grammaticalized in other languages (e.g. between 'property concept words' and 'action/event words';

Thanks to members of the audience at a presentation in Bochum, 7 June 2001, for comments on some of the ideas in this chapter, and especially to Eva Schultze-Berndt and Nikolaus Himmelmann for encouragement and advice. 
Enfield, 2004). There is no distinct class of adverbs. Adverbial meanings are often expressed by verbs in certain constructional slots.

The following examples show vaj2 'fast' as a main predicate (1), as a modifier in a noun phrase (2), and as an adverbial modifier of a main predicate lè̀nı 'run/go' (3):'

(1) lot1 khan2 nii4 vaj2

vehicle CLF this fast

'This vehicle is fast.'

(2) lot1 vaj2 khan2 nii4 ngaam2

vehicle fast CLF this beautiful

'This fast vehicle looks good.'

(3) lot1 khan2 nii4 lèèn vaj2

vehicle CLF this run fast

'This vehicle goes fast.'

The basic structure of the Lao clause is as follows ('AM' stands for 'aspectmodality marking', which may occur on either side of the verb):

\section{(4) Left Position-Subj-AM-[V (OвJ)]-AM-Final-Ptcls- RIGHT POSITION}

Noun phrases in almost any position may be ellipsed if their referent is contextually retrievable. Left aspect-modality marking may occur no more than once per clause. There are many ways in which two verbs can appear together in a single clause, involving adjunction, complementation, or compounding (Enfield 2003; to appear). An important point in the context of analysing secondary predication in this language is the complete lack of overt morphological marking of relationships between elements within complex structures. Many languages have various forms of the verb showing distinctions in 'finiteness', indexed by presence or lack of tense/ aspect/modality marking, dedicated nonfinite forms, patterns of agreement or cross-referencing, which all can help to decide what role a certain element

\footnotetext{
1 Transliteration used here follows IPA convention except for velar nasal $/ n g /$, glottal stop $/ q /$, mid-high front vowel $/ \hat{e} /$, low front vowel $/ e /$, central vowel (schwa) $/ e /$, low central vowel $/ a /$, high back unrounded vowel $/ \dot{u} /$, low back vowel $/ \hat{o} /$. Tones are represented by numbers following each syllable ( $\theta=$ unstressed/atonal, $1=/ \mathrm{mid}$ level $/, 2=/ \mathrm{high} \mathrm{rising} /, 3=/ \mathrm{low} \mathrm{rising} /, 4=/$ high falling $/$, $5=$ /low falling/).

Examples are drawn from a corpus of spontaneous texts (including personal narratives, procedural descriptions, folk tales, conversations, and the like) collected in Vientiane in 1996 and 1997. Numbers in brackets following the translation of each example refer to paragraph number in text transcriptions. Examples with no such reference number are constructed in consultation with native speakers.
} 
has. In analysing depictive constructions in a wide range of languages, Schultze-Berndt and Himmelmann (2004) make extensive reference to patterns of agreement and other overt morphological marking of the role of different predicates in complex expressions (see also Ch. 1, this volume). In Lao, however, there is no agreement, no case-marking, no explicit finiteness distinction. There are, however, overt markings of aspect and modality (e.g. negation, perfective marking, illocutionary particles) which can be useful in analysing the structural status of certain elements in complex expressions. Also useful are tests involving movement and paraphrase. These are employed in the discussion below.

The chapter is structured as follows. In section 12.2, I discuss participantoriented expressions ${ }^{2}$ involving unmarked verbs in $V_{1}$ and $V_{2}$ structures, first where the depictive element is $V_{2}$, then where the depictive element is V1. Some ambiguities in analysis are discussed. While these structures can and often do convey participant orientation, they are not dedicated depictive constructions, since the same structures are also used to express adverbial (manner) and resultative meanings. That is, they are GENERAL ADIUNCT CONSTRUCTIONS in terms of the distinctions proposed in the introduction to this volume.

In section 12.3, I look at two ways in which nominals can contribute to depictive expressions. They may appear as predicative nominal phrases, or in an adjunct structure headed by the verb pên 3 (elsewhere a copula 'be'). The nominal hosted by pên 3 describes the physical (or other) form of one of the main clause arguments. Once again, these are not dedicated depictive but general adjunct constructions, since the same structures may also be used with manner adverbial and resultative meanings. Section 12.4 concludes.

\subsection{Depictive secondary predication by unmarked verb}

Many unmarked combinations of verbs in Lao clauses can be analysed as involving secondary predication. A predicative element (typically a member of the verb class) makes a predication in addition to a main or primary predication. This secondary predicative element may be omitted without changing the basic semantics of the primary predication, and in this sense secondary predicates are always adjuncts. The term SECONDARY PREDICATION refers to this phenomenon generally, and the various semantically definable subtypes may be termed Depictive, adverbial, and resultative (perhaps among others in addition). I use the term EXPRESSION to refer to structures

\footnotetext{
${ }^{2}$ For the term PARTICIPANT-ORIENTED EXPRESSION, see the introduction to this volume.
} 
with a certain meaning, but where the structure is not dedicated to expressing just that meaning. Thus, a DEPICTIVE EXPREsSion is a complex structure in which a secondary predication has depictive meaning.

Semantically, I make the following distinctions among secondary predications (although the distinctions are in practice not always neat):

- depictive Expresses the incidental and transient state of one of the participants in a primary predication. There is no connection of cause, result, or manner between the two predications. Stock examples are She ate the fish raw and He gave the lecture nude.

- Adverbial (MANNer) Says something about the manner of the primary predication, as in He ate fast and She spoke hesitantly.

- RESULTATIVE Expresses something that happens or is the case because the primary predication takes place. Typical examples are She licked the platter clean and He broke it in half.

\subsubsection{V/2 depictives}

Many clauses in Lao are of the form $\left(\mathrm{NP}_{1}\right) \mathrm{V}_{1}\left(\mathrm{NP}_{2}\right) \mathrm{V}_{2}$, where $\mathrm{V}_{1}$ and $\mathrm{V}_{2}$ are in a relationship of either coordination or subordination (with only the former normally allowing insertion of clause-linking particles without altering the truth-conditional meaning of the complex expression). In the latter case, either $V_{1}$ or $V_{2}$ may be the secondary predicate. We first consider structures in which $\mathrm{V}_{2}$ conveys a depictive meaning.

A prototypical if not archetypal depictive secondary predicate is 'raw'. It predicates a changeable/transient state of a (usually edible) primary predicate object argument, and has little if any bearing on how the action involving that object (typically 'eating') is carried out. While the word order of English distinguishes between He eats meat raw versus He eats raw meat, an equivalent construction in Lao makes no surface distinction:

(5) $\operatorname{man} 2$ kin3 siin4 dip2

3SG eat meat raw

i. 'S/he eats meat raw.'

ii. ' $S$ /he eats raw meat.'

In the 'depictive' reading (5i), the main predication is the idea that ' $\mathrm{S} / \mathrm{he}$ eats meat', and predicated in addition to this is the idea that the meat is, at this time, in the state of being 'raw'. A verb such as vajz 'fast' can appear in the same position, with adverbial meaning (see example (3), above). The difference here is that the secondary element vaj2 'fast' does not make a predication about the meat, but about the manner of the event. 
In the (5ii) reading, dip2 'raw' is a nominal modifier, forming a constituent with the nominal head siin4 'meat' to give a noun phrase siin 4 dip2 'raw meat' which could, for example, function as a subject argument:

$$
\begin{aligned}
& \text { siin4 dip2 bò diiz } \\
& \text { meat raw NEG good } \\
& \text { 'Raw meat is no good.' }
\end{aligned}
$$

The difference between the two interpretations of the role of dip2 'raw' in (5) corresponds in many other languages to an overt morphosyntactic distinction (e.g. in patterns of agreement, word order, derivational morphology). The distinctions in Lao are covert in (5). They come to light when we look at possibilities for movement, paraphrase and insertion. The distinction between an analysis of a nominal followed by a stative predicate (as in (5)) as a complex noun phrase (with $\mathrm{N}+$ modifier structure) or as a simple noun phrase $(\mathrm{N})$ followed by a secondary predicative element can be made explicit if the noun phrase is more complex (e.g. with a determiner included, as in $(7,8))$, or 'extracted' and fronted $(9,10)$ :

$$
\begin{array}{llllll}
\text { man2 } & \text { siø } & \text { kin3 } & {\left[\begin{array}{l}
\text { siin4 } \\
\text { dip2 }
\end{array}\right.} & \text { nii } 4]_{\mathrm{NP}} \\
3 \mathrm{SG} & \text { IRR } & \text { eat } & \text { meat } & \text { raw } & \text { this }
\end{array}
$$

'S/he's going to eat this raw meat.' [does not entail that she'll eat it raw]

$$
\begin{aligned}
& \text { man2 siø kin3 }\left[\begin{array}{lll}
\text { siin4 } & n i i 4
\end{array}\right]_{\mathrm{NP}} \text { dip2 } \\
& \text { 3SG IRR eat meat this raw }
\end{aligned}
$$

'S/he's going to eat this meat raw.'

(9) $\quad\left[\begin{array}{llllll}\text { siin4 } & n i i 4\end{array}\right]_{\mathrm{i}} \operatorname{man} 2$ siø $k i n 3 \sigma_{i} \quad$ dip2 meat this 35 G IRR eat raw 'This meat, s/he's going to eat raw.'

(10) $\quad\left[\begin{array}{llllll}\sin 4 & \text { dip2 } & \text { nii4 }\end{array}\right]_{\mathrm{i}}$ man2 sio $\operatorname{kin} 3 \varphi_{i}$ meat raw this $3 S G$ IRR eat

'This raw meat, s/he's going to eat.' [does not entail that she'll eat it raw]

Such tests using constituent extraposition can reveal differences in grammatical behaviour between potentially depictive elements such as dipz 'raw' in (11a) and modifiers such as ñaj1 'big' in (12a). The (b) examples show that the nominal head of the object argument can be fronted in the case of the depictive expression, but not in the case of the noun-modifier expression:

(11) a. man2 $\begin{array}{lll}\text { kin3 } & \sin 4 & \text { dip2 } \\ 3 \text { SG } & \text { eat meat raw }\end{array}$

'S/he eats meat raw.' (also possible: 'S/he eats raw meat.') 
$384 \quad$ N. J. Enfield

b. $\sin 4$ man2 kin3 dip2

meat 3sG eat raw

'Meat, s/he eats raw.'

(12) a. man2 juu1 hùan2 ñaj1

3SG live house large

'S/he lives in a large house.'

b. *hùan2 man2 juu1 ñaj1

house 3SG live large

(A house, s/he lives in large.)

A final point concerns the yes-answer properties of the two readings of (5). Ambiguity in a question between depictive and noun-modifier readings (i.e. (5i) vs. (5ii), above) can be removed in an affirmative answer (in favour of the depictive reading), by using both the primary and secondary verb together (without the object argument), as opposed to just the primary predicate (in which case the response remains ambiguous):

(13) Q: man2 kin3 siin4 dip2 bòò

3sG eat meat raw $Q$

i. 'Does s/he eat meat raw?'

ii. 'Does s/he eat raw meat?'

A1: $\operatorname{kin} 3$ dip2

eat raw

'(Yes, s/he) eats (it) raw.' [depictive interpretation]

A2: kin3

eat

i. '(Yes, s/he) eats (it).' [non-depictive interpretation, preferred]

ii. '(Yes, s/he) eats (it raw).' [depictive interpretation, possible]

It seems that particular combinations of main verb and depictive element in expressions such as (5), (8), (9), and (11b) are associated with familiar, conventionalized combinations of primary and secondary predications. This does not mean that the combination must be typical in itself, and in fact it may be that depictive expressions are more likely to be used when the combination of predications is pragmatically marked (as, for example, in the celebrated case of 'eating meat raw'). But the combination must make sense with reference to some kind of conventionalized or sensible scenario (i.e. as 'eating meat raw' presupposes a contrasting norm of 'eating meat cooked'). Out of context, a V 2 depictive jênz 'cool' is perfectly natural with a primary predication kinz 'eat/consume' but not with 
tak2 'scoop':

(14) nam4, man2 dajø kin3(/ $/^{\star}$ taks) jên3

water 3SG attain eat(/scoop) cool

'Water, he drank cool.' (not: 'Water, he scooped cool.')

It is my impression that depictive expressions are subject to pragmatic restrictions on specific combinations of primary and secondary predicate, related to the relevance and/or conventionality of the combination (see Enfield $2002 a$ for a study of this phenomenon in associated postural constructions). The issue needs further exploration.

Participant-oriented expressions such as (5), (8), (9), and (11b), involving dip2 'raw', are not formally distinct enough from secondary predicates of other kinds (e.g. adverbials) to be regarded as distinct 'depictive constructions'. The following examples, involving vajz 'fast' as a V2 adverbial expression, show the same grammatical properties as have been illustrated for unmarked $V_{2}$ depictive expressions: (a) manner versus modifier ambiguity (15), (b) disambiguation by different insertion of demonstrative $(16 a, b),(c)$ disambiguation by topicalization of the object nominal head alone (17a) vs. object nominal together with secondary predicate (17b):

(15) man2 khap2 lot1 vaj2

3SG drive car fast

i. 'He drives cars fast.'

ii. 'He drives fast cars.'

(16) a. man2 khap2 lot1 vaj2 nii4

3SG drive car fast this

'He drives this fast car.'

b. man2 khap2 lot1 nii4 vaj2

3sG drive car this fast

'He drives this car fast.'

(17) a. lot1 man2 khap2 vaj2

car 3sg drive fast

'Cars, he drives fast.'

b. lot1 vaj2 man2 khap2

car fast 3SG drive

'Fast cars, he drives.'

12.2.2 V1 depictives

Some verbs, such as verbs of posture and wearing, can have depictive function in $V_{1}$ position. These verbs include in their internal semantics an event 
(e.g. 'putting on a hat' or 'moving into a sitting position') followed by a resultant state (e.g. 'wearing a hat' or 'being in sitting position'). V1-V2 strings with posture verbs in $\mathrm{V}_{1}$ position are thus interpretable as either a series of actions (e.g. 'sit and then read') or an overlapping of state and action (e.g. 'sitting [i.e. in the state of having sat] and reading at the same time': see Enfield 2002b). These can appear to be compounds ('He drunk-drives'), subordinating adverbial constructions ('He drunkenly drives'), or clause chains ('He [gets] drunk [and then] drives'). The distinction is difficult to make in the absence of simple morphosyntactic tests, and tests such as paraphrase and movement can upset the integration of such structures and make judgements difficult.

Here are two examples of $V_{1}$ depictive expressions:

(18) man2 nang1 qaan1 pùm4

3 SG sit read book

'He sat reading a book.' (or: 'He read a book sitting.')

(19) man2 maw2 maà hùan2

3sG drunk come house

'He came home drunk.'

It is possible, but dispreferred, for the depictive element in these expressions to appear after the primary predicate:

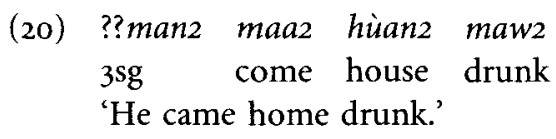

The preference for the constituent order in (18) and (19) is presumably due to the nature of the 'depictive' element being an expression of 'processfollowed-by-result' (e.g. 'sitting-followed-by-being-seated', 'putting-hat-onfollowed-by-wearing-hat', 'getting-drunk-followed-by-being-drunk'). The depictive expression needs to occur in $\mathrm{V}_{1}$ position to preserve the iconicity of the process occurring before the state, which then holds over the primary predicate. This is not the case when the depictive element expresses a simple state (which does not inherently presuppose a preceding process) such as 'raw', 'fresh', or 'cool' (cf. section 12.2.1 above).

\subsection{Use of nominals in depictive expressions}

Nominals are used in depictive expressions in Lao in at least two ways. First, certain constituents which appear formally to be noun phrases (but which turn out to be stative predicates) can have depictive function. Second, a type 
Depictive and other secondary predication in Lao $\quad 387$

of adjunct headed by a copula verb pên 3 hosts nominals with a range of depictive, adverbial, and resultative meanings.

12.3.1 Body part noun + stative verb as $V_{2}$ depictive

An apparent case of an NP in depictive function is as follows:

(21) man2 mùas hùans mùù paw1

3SG return house hand empty

'S/he returned home empty-handed.'

While the sequence mùù pawı (hand empty) can indeed be analysed as an NP meaning 'empty hand(s)', in this context it is a predicative NP, not a referential NP-i.e. it is predicating a state of affairs ('having empty hands') rather than a thing ('empty hands'). Nominals in Lao may occasionally be used predicatively - e.g. in equational expressions such as phuu5-nan 4 qaaj4 khoòj5 (person-that brother I) 'That person [is] my brother'. But they are quite restricted in this function. Most importantly, they can take no verbal trappings (negation, aspect marking, etc.) whatsoever. The sequence mùù paw1, however, is of a different type.

As a general rule in Lao, sequences of the form 'body part noun' + 'stative verb' can function as predicates, taking full verb trappings (see Clark 1996 on this phenomenon in South-East Asian languages more generally). The following examples show the sequences taa 3 khiaw3 (eye green) (elsewhere a noun phrase 'green eye(s)') and phom3 dè̀ng3 (hair red) (elsewhere a noun phrase 'red hair') as main predicates, taking direct negation and irrealis marking, respectively: ${ }^{3}$

(22) khon2 laaw2 bòø taa3 khiaw3

person Lao NEG eye green

'Lao people [are] not green-eyed.'

(23) luuk4 caw4 caø phom3 dè̀ng3

child 2SG IRR hair red

'Your child will [be] red-haired.'

Thus, the depictive element mùù 2 paw1 'empty hand(ed)' in (21) can be analysed as a predicate in $V_{2}$ position, and is therefore not a genuine case of an unmarked 'nominal' having depictive function. Instead, it belongs to the type of construction discussed in 12.2.1 above.

3 This is similar to a 'topic-comment' construction, but not the same. The difference here concerns the placement of verb marking (negation, irrealis marking). In a regular topic-comment construction, verb marking occurs immediately before the verb (e.g. ton4-sakz baj3 bò nooji (tree-teak leaf not small) "Teak trees, [the] leaves are not small'). 
12.3.2 Depictive/resultative/adverbial adjuncts marked by pên3 'be'

A construction which involves an adjunct headed by the copula verb pên often has depictive meaning, but also shows resultative and adverbial meanings. In these cases, the complement of pênz 'be' is always a nominal.4 In the following example, the verb phrase hòp5 phuuz 'carry [a] mountain' takes an adjunct formed by pênz and its nominal complement nuajı (a classifier):
(24) bak2 ñak1 kum3phan2 hòò5 phuu2 pên3 nuaj1 FAM.M ogre $K$. carry.in.arms mountain be CLF
'The Ogre Kumphan carried the mountain whole.' (201)

In (24), the word nuaj1 is the classifier for mountains (among other things), and the adjunct pên 3 nuajı in this context means 'whole' or 'as a unit'. The expression is depictive in that it makes an extra predication about the state (as 'whole' rather than in parts) of one of the participants involved in the main predication (i.e. the object of hoops 'carry in arms'). The use of sortal classifiers in pênz-adjuncts with the meaning 'whole, as a unit' is fully productive in Lao.

The marker of the pênz-adjunct construction is the verb pênz 'be', which has a range of main verb functions in other contexts. For example, it may serve as a copula (25), and as a predicator of illness (26):

(25) tòòn3 nan4 khò̀j5 pên3 nak1-hian2

time that $1 \mathrm{sG}$ be student

'At that time, I was a student.' (243)

(26) pên3 khaj5

be fever

'[They] had fever.' (139)

It may also appear as a postverbal modal expressing inherent, learnt, or acquired ability: 5

(27) hòq2 bòø pênz dêê4

fly NEG be PTCL

'[He] couldn't fly, you know.' (169)

\footnotetext{
4 There are only a few exceptions. For example, the sequence pênz pokzkatiq2 (be normal/regular) (where pokskatiqz is a verb), is a common adverbial adjunct meaning 'in normal/regular fashion'.

${ }^{5}$ In some uses, and in some dialects, pênz may be used with this meaning as a preverbal complement-taking predicate-cf. Stung Treng Lao (NE Cambodia) bòø pên3 vaw4 laawz (NEG 'be' speak Lao) 'don't know how to speak Lao' versus Vientiane Lao vaw4 laawz bòø pênz (speak Lao NEG 'be') 'don't know how to speak Lao'.
} 


(28) mùng2 kaø hêtı kin3 bòø pên3 dòòs5
2SG FOC make eat NEG be PTCL
'You don't know how to cook [them]!' (42)

The pênz-adjunct makes a secondary predication which can express meanings ranging from depictive to resultative to adverbial. Some examples are difficult to categorize uniquely, since they combine elements of more than one adjunct type.

Like example (24) above, the following two examples have genuinely depictive semantics, in that the secondary expressions describe the form or state of the main clause object at the time of the main verb event taking place (with no necessary relation of cause or manner holding between the two predications):

(29) Khaw3 kin3 siin4 pên3 tò̀n1

3PL eat meat be chunk

'They ate [the] meat in chunks.'

(30) mans hèèngs lèø kèq2 qòòk5 pên3 phèèn1 cia4 3SG dry PTCL scrape/peel exit be CLF/sheet paper '[When] it's dry, then peel it off in/as paper sheets.' (113)

Similarly, in the next example, the penz-adjunct is depictive in that it describes the physical arrangement of the argument of the main clause 'they' during the time that the action of the main clause takes place:

(31) khaw3 nang1 kin3 khaw5 pên3 thèèw3 $3 \mathrm{PL}$ sit eat rice be row 'They sat and ate in rows.'

A final example is perhaps more abstract, where 'being in English' is a predication about the 'form' of a story:

(32) man2 law1 luang1 nii4 pên3 phaassaa3 qang3kit2
3sg tell story this be language English
'He told this story in English.'

Pên 3 adjuncts can express a state of the primary predicate object which is not incidental to the primary predication but rather results from it. The main semantic difference between these expressions and genuine depictive expressions is the temporal relationship between the two predications. In these cases, the secondary predication is true after the primary predication, while in the case of depictives, the two predications overlap temporally. There are a number of subtypes of these 'state as result' secondary predications. 
For example, the pên 3 adjunct may express the form of the primary predicate object as resulting from the primary predication, in terms of physical transformation or modification $(33,34)$, a transformation in status or social role (35), or coming into existence (36):

(33) maa2 paat5 pên3 siì liam1 come slice be four sides

'Bring [the wood and] cut [it] into four-sided [pieces].' (114)

(34) liaw3 beng1 sùak4 khanaat5 nii4 pùaj1 pên3 phong3 turn look rope size this dissolved be powder '[They] turned [and] looked [and saw] a rope of such size dissolved into powder.' (133)

(35) phen1 leej2 haj5 buat5 pên3 phaq1 3 HON then give ordain be monk 'Then he had [me] ordained [as] a monk.' (321)

(36) can3thaa2 mè̀̀-khaw4 keet5 luuk4 pên3 sat2 C. queen born child be animal 'Chantha the queen gave birth to children [as] animals.' (153)

There are also examples of adjuncts in pên 3 which are primarily manneradverbial, such as the following:

(37) man2 khap2 lot 1 pên3 labiap5 3SG drive vehicle be regulation/orderliness

'He drives in an orderly way.'

Finally, some pênz adjuncts are comparable to 'predicative complements' such as I consider him a brother which in English are morphosyntactically and semantically quite distinct from depictive complements:

(38) kuu3 thùù3 khon2 nii4 pên3 qaaj4 1sG regard person this be older.brother 'I regard this person [as a] brother.'

Semantically, this is not depictive. 'Being the speaker's brother' is not being asserted in the pênz adjunct merely as an incidental state of the primary predicate object. Clearly, there is a semantic subordination of 'being brother' to 'regarding' that something be the case. Unlike the examples we have seen so far, in this case the pênz adjunct cannot be omitted without changing the meaning of the main verb thùü. (This is in explicit contrast to, say, example (35).) In (38), thùü means 'regard, consider'. If the pênz adjunct were removed, the meaning of the verb thùu 3 would be 'hold, carry', and the 
sentence as a whole would mean 'I carried this person' (cf. English I regarded this person as a brother versus I regarded this person).

\subsection{Summary}

Depictive secondary predications are commonly expressed in Lao by the use of an unmarked predicative element (verb) in addition to the primary predicate. The status of secondary verbs as secondary is not overtly manifest in Lao (e.g. by distinct nonfinite forms). The nature of the grammar denies the analyst patterns of agreement or verb finiteness, thus making Lao-like any heavily isolating language-a useful addition to crosslinguistic research on a topic which has hitherto centred heavily around analysis in terms of those morphosyntactic indices. Secondary predicative verbs appear in $\mathrm{V}_{1}-\mathrm{V}_{2}$ sequences, with sub-types in which either the $V_{1}$ or $V_{2}$ element makes the secondary predication. $V_{2}$ depictives express simple states (such as 'raw' or 'fresh'), while V1 depictives express post-states which are the inherent outcome of prior events (such as 'seated/having-sat' or 'drunk/having-drunk'). Nominals may be hosted in adjuncts headed by the verb pên3 'be', where the nominal describes the form of one of the primary predicate participants. A common use of this construction features a classifier, giving the meaning 'whole' or 'as a unit'. The pên3 adjunct can also express not just form but resultant form, thus expanding beyond simple depictive meaning.

These various structures have broader secondary predicative function, being also able to express adverbial and resultative meanings. Since they are not restricted to the expression of depictive semantics only, I conclude that there is no dedicated depictive construction in Lao. Nevertheless, the subdistinctions among depictive and other functions of these secondary predicate structures are essentially semantic in nature, and I would be surprised if such sub-distinctions did not correspond to some kind of demonstrable distinction in grammatical behaviour, however subtle. 